\title{
Shigeki Kubota $\oplus^{1,2}$, Tetsuya Abe ${ }^{2}$, Hideki Kadone ${ }^{3}$, Yukiyo Shimizu ${ }^{4}$, Toru Funayama ${ }^{2}$, Hiroki Watanabe $\odot^{5}$, Aiki Marushima ${ }^{5}$, Masao Koda ${ }^{2}$, Yasushi Hada ${ }^{4}$, Yoshiyuki Sankai ${ }^{6}$, Masashi Yamazaki ${ }^{2}$
}

\begin{abstract}
${ }^{1}$ Division of Regenerative Medicine for Musculoskeletal System, Faculty of Medicine, University of Tsukuba, Tsukuba, Japan, ${ }^{2}$ Department of Orthopaedic Surgery, Faculty of Medicine, University of Tsukuba, Tsukuba, Japan, ${ }^{3}$ Center for Innovating Medicine and Engineering (CIME), University of Tsukuba Hospital, Tsukuba, Japan, ${ }^{4}$ Department of Rehabilitation Medicine, University of Tsukuba Hospital, Tsukuba, Japan, ${ }^{5}$ Department of Neurosurgery, Faculty of Medicine, University of Tsukuba, Tsukuba, Japan, ${ }^{6}$ Faculty of Systems and Information Engineering, University of Tsukuba, Tsukuba, Japan
\end{abstract}

Context/Objective: The hybrid assistive limb (HAL) is a wearable exoskeleton robot that assists walking and lower limb movements via real-time actuator control. Our aim was to clarify the safety and feasibility of using the HAL robotic suit for rehabilitation in patients with severe thoracic myelopathy due to ossification of the posterior longitudinal ligament (T-OPLL).

Design: Uncontrolled case series; pre- and post-intervention measurement.

Setting: In-patient rehabilitation unit.

Intervention: HAL training was provided in 60-minuts session, 2-3 sessions per week, for a total of 10 sessions. HAL training was initiated on average 27.5 days post-surgery.

Patients: Eight patients (four males and four females; mean age, $60.9 \pm 10.2$ years) with severe myelopathy, who had undergone posterior decompression with instrumented fusion, were enrolled.

Outcome Measures: Gait speed, step length and cadence were measured along a 10-m walkway every session. The American Spinal Injury Association (ASIA) motor score (lower extremities) and Walking Index for Spinal Cord Injury (WISCI) II were also evaluated at baseline and after 10 sessions. The Japanese Orthopaedic Association (JOA) score was calculated over time after surgery.

Results: All participants completed the 10 training sessions, with no serious adverse effect noted. Gait speed, step length and cadence improved over time. Both the WISCI-II and ASIA motor (lower extremities) scores improved from baseline after 10 sessions. The JOA score improved over time post-surgery.

Conclusion: HAL training can be feasibly initiated in the early postoperative period, without severe adverse events in patients, with T-OPLL-related severe gait disturbance.

Keywords: Hybrid assistive limb, Ossification of the posterior longitudinal ligament, Postoperative acute phase, Robot treatment, Rehabilitation, Exoskeleton robot Correspondence to: Shigeki Kubota, Division of Regenerative Medicine for
Musculoskeletal System, Department of Orthopaedic Surgery, Faculty of
Medicine, University of Tsukuba, 1-1-1, Tennodai, Tsukuba, lbaraki, 305-
8575, Japan; Ph:+81-29-853-3219. Email: s-kubota@md.tsukuba.ac.jp;
skubota@tsukuba-seikei.jp

Color versions of one or more of the figures in the article can be found online at www.tandfonline.com/yscm.

\section{Introduction}

Ossification of the posterior longitudinal ligament (OPLL) of the thoracic spine is a heterotopic ligamentous ossification that may cause spinal cord 
compression, due to a narrowing of the spinal canal by the ossified ligaments, resulting in severe myelopathy. Surgical treatment for spinal cord decompression is recommended for patients with functional disorders, such as gait disturbance, bladder disorder and a myelopathic hand, who are resistant to conservative therapy. ${ }^{1}$ Postdecompression, patients participate in a program of rehabilitation to improve posture and movement.

The hybrid assistive limb (HAL) robot is a wearable exoskeleton that provides real time assist an individual for walking and limb movements via actuators (i.e. power units) mounted on the hip and knee joints, bilaterally (Fig. 1). ${ }^{2-5}$ Three types of biological information are used in the actuated control: (1) bioelectric signals, detected through electrodes placed on the anterior and posterior surfaces of the thigh, over the rectus femoris, gluteus maximus, hamstrings, and lateral broad muscle; (2) movement information, detected through angular sensors located over the hip and knee joints, bilaterally; and (3) information about the movement of the body center of gravity, detected by force-pressure sensors in the shoes. Therefore, the HAL can provide assist control to the sagittal plane movements of the hip and knee, bilaterally.

Previous studies have reported on the feasibility and efficacy of HAL training in the rehabilitation of patients with impaired walking due to chronic multifactorial conditions ${ }^{6}$ and to various underlying conditions, including musculoskeletal ambulation disorder, ${ }^{7}$ spinal cord injury, ${ }^{8-14}$ stroke, ${ }^{15-22}$ knee joint disease, ${ }^{23-26}$ and brachial plexus injury. $^{27,28}$ However, the applicability of HAL training in patients with OPLL has only been evaluated in a few case reports to date. ${ }^{29-32}$ Accordingly, the aim of

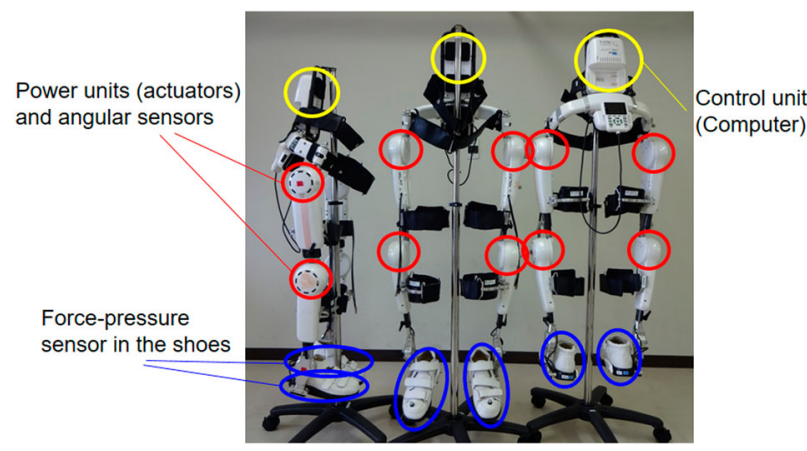

Figure 1 The robot suit hybrid assistive limb (HAL). The HAL includes power units (actuators), angular sensors in the hip and knee joints, bilaterally, a control unit (computer) on the back, and force-pressure sensors in the shoes. The power units consist of angular sensors and actuators on the bilateral hip and knee joints. Bioelectric signals are detected through the electrodes on the anterior and posterior surfaces of the wearer's thigh. These various bioelectric signals are processed by a control unit (computer). our study was to clarify the safety and feasibility of HAL training in patients who underwent spinal cord decompression for a thoracic OPLL (T-OPLL), in the acute or subacute postoperative periods. Therefore, we investigated as follows; whether there were severe and mild adverse events such as extreme fatigue and skin trouble after HAL walking training, whether there were severe fatigue during HAL walking training and dropout due to extreme fatigue, and postoperative day of HAL training start, as the safety and feasibility of HAL training.

\section{Materials and methods Trial design}

The present study was designed as a one-arm, open label phase $1 / 2$ trial to show the safety and feasibility of HAL training in patients with a severe thoracic myelopathy patients secondary to T-OPLL, with training undertaken during the acute or subacute postoperative periods.

\section{Inclusion/ exclusion criteria}

The inclusion criteria were as follows. (1) T-OPLL with gait disturbance treated via posterior decompression with instrumented fusion (PDF) (Fig. 2); (2) requiring physical assistance or assistive devices for sit-to-stand, stand-to-sit and walking after surgery: (3) ability to understand the explanation of the study and to express consent or refusal; (4) body size that could fit in the robotic suit HAL (height, 145-180 cm; maximal body
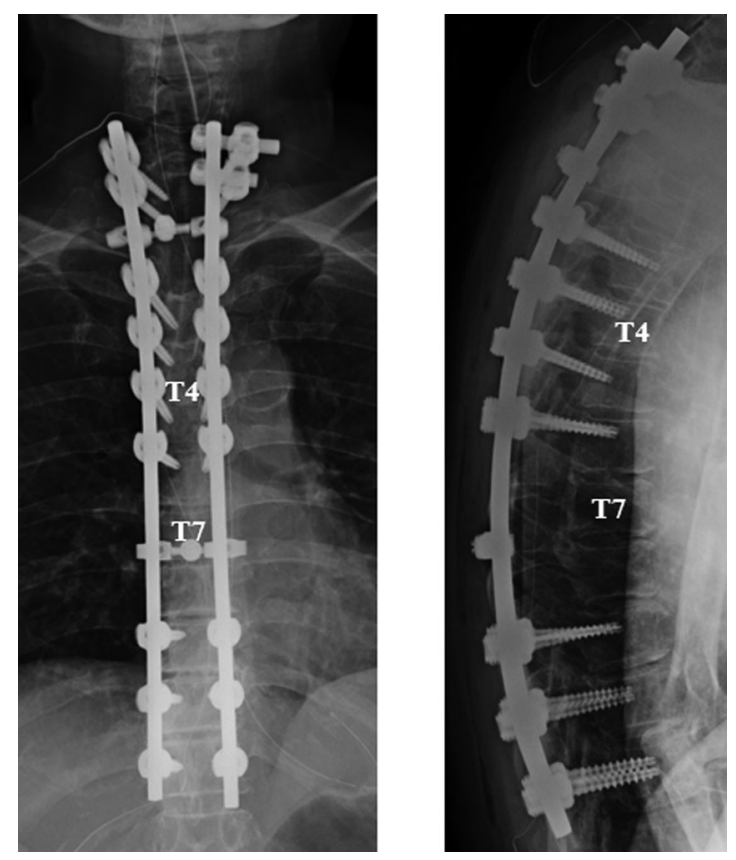

Figure 2 Postoperative radiographic image after posterior decompression with instrumented fusion (PDF) from C3 to T11 (case 8). 
weight, $90 \mathrm{~kg}$ ); and (5) ability to undergo the usual postoperative programs of physical and occupational therapy. The exclusion criteria were (1) inadequately controlled cardiovascular disorders; (2) inadequately controlled respiratory disorders; (3) intellectual impairments that limit the ability to understand instructions; (4) moderate-to-severe joint disorders, including contractures at lower limb joints; and (5) moderate-tosevere involuntary movements, such a ataxia, or impairments of postural reflexes in the trunk or lower limbs.

\section{Patients}

The study group was formed of 8 postoperative T-OPLL patients, with severe myelopathy, who underwent PDF (four males and four females; mean age, $60.9 \pm 10.2$ years); relevant demographic and clinical characteristic of our study group are summarized in Table 1. Usual rehabilitation, including training for sitting, standing and walking, was initiated immediately after surgery. HAL training was initiated once a patient was able to assume and maintain a sitting position. Just prior to HAL training, 4 patients required a walker for level ground walking (cases 1, 4, 5, and 7), 2 patients required 1-person assist in addition to a walker for level ground walking (cases 2 and 3), 1 patient required 1-person assist for walking between parallel bars (case 8), and 1 patient was unable to walk (case 6).

\section{Treatment with HAL}

For safety, patients wore the HAL while standing upright with a walking device (All-in-One Walking
Trainer; Healthcare Lifting Specialist, Denmark) and a harness. Three individuals assisted in setting up the device (one behind and one on each side), which was completed in $2.5-3$ min. All HAL training was performed with the additional support of the All-in-One Walking Trainer (Fig. 3, Online Resource 1). Training was performed in 60-minutes sessions, held 2-3 times per week, to a total of 10 sessions. The duration of HAL-assisted walking was approximately 15-20 min in total, with sufficient rest period provided between walking trials. The walking distance was initially adjusted to a patients' condition, with the distance gradually increased over the course of the treatment. This study primarily used the cybernic voluntary control (CVC) mode of the HAL exoskeleton, which allows the operator to adjust the degree of physical support provided to the patient's comfort.

\section{Adverse events}

Adverse events were defined as any untoward symptom, disease or signs of such (including clinical laboratory data abnormalities) and, therefore, not specifically related to the HAL, which is the product under investigation. Adverse events included: death, life-threatening condition, disability or incapacity, potential disability, and hospitalization or extension of hospital stay. Extension of hospital stay due to surgery for the original disease was not considered an adverse event. All adverse events were reported using the ICH codes (International

Table 1 Clinical characteristics of the eight patients who received treatment with hybrid assistive limb (HAL).

\begin{tabular}{|c|c|c|c|c|c|c|c|c|c|}
\hline $\begin{array}{l}\text { Case } \\
\text { no }\end{array}$ & $\begin{array}{l}\text { Age } \\
\text { (year)/ } \\
\text { sex }\end{array}$ & Diagnosis & $\begin{array}{l}\text { Most } \\
\text { stenotic } \\
\text { level }\end{array}$ & Operation & $\begin{array}{l}\text { Instrumented } \\
\text { fusion levels }\end{array}$ & $\begin{array}{l}\text { HAL } \\
\text { start } \\
\text { (POD) }\end{array}$ & $\begin{array}{l}\text { Ambulation of } \\
\text { before HAL }\end{array}$ & $\begin{array}{c}\text { Assistive } \\
\text { Device of } \\
\text { before HAL }\end{array}$ & Reference \\
\hline$\overline{1}$ & $43 / M$ & $\begin{array}{l}\text { Thoracic } \\
\text { OPLL }\end{array}$ & T10/11 & PDF & T8-L3 & 13 & Supervision & Walker & 31 \\
\hline 2 & $63 / F$ & $\begin{array}{l}\text { Thoracic } \\
\text { OPLL }\end{array}$ & $\mathrm{T} 4 / 5$ & PDF & T1-9 & 44 & 1 assistance & Walker & 30 \\
\hline 3 & $67 / F$ & $\begin{array}{l}\text { Cervical and } \\
\text { thoracic } \\
\text { OPLL }\end{array}$ & $\mathrm{T} 2 / 3$ & PDF & C3-T6 & 13 & 1 assistance & Walker & - \\
\hline 4 & $58 / \mathrm{M}$ & $\begin{array}{l}\text { Thoracic } \\
\text { OPLL }\end{array}$ & $\mathrm{T} 2 / 3$ & PDF & C3-T6 & 41 & Supervision & Walker & - \\
\hline 5 & $77 / F$ & $\begin{array}{l}\text { Thoracic } \\
\text { OPLL }\end{array}$ & $\mathrm{T} 11 / 12$ & PDF & T9-L2 & 15 & Supervision & Walker & - \\
\hline 6 & $64 / M$ & $\begin{array}{l}\text { Cervical and } \\
\text { thoracic } \\
\text { OPLL }\end{array}$ & $\mathrm{T} 6 / 7$ & PDF & $\mathrm{T} 2-12$ & 43 & 2 assistance & NA & - \\
\hline 7 & $52 / M$ & $\begin{array}{l}\text { Cervical and } \\
\text { thoracic } \\
\text { OPLL }\end{array}$ & $\mathrm{T} 2 / 3$ & PDF & T1-9 & 18 & Supervision & Walker & - \\
\hline 8 & $63 / F$ & $\begin{array}{l}\text { Cervical and } \\
\text { thoracic } \\
\text { OPLL }\end{array}$ & $\mathrm{T} 7 / 8$ & PDF & C3-T11 & 33 & 1 assistance & NA & - \\
\hline
\end{tabular}

OPLL, ossification of the posterior longitudinal ligament; PDF, posterior decompression with instrumented fusion; POD, postoperative day; NA, not applicable. 


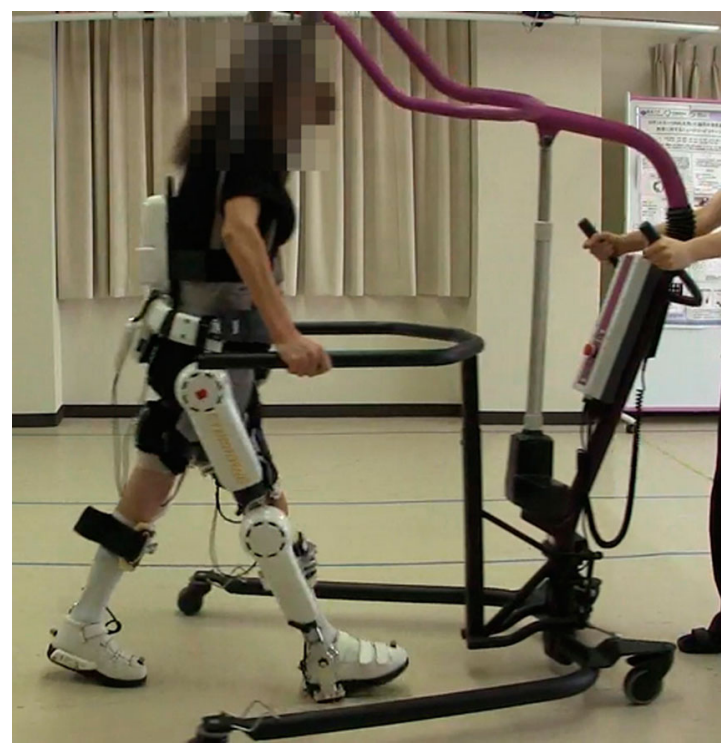

Figure 3 Treatment with hybrid assistive limb (HAL) with a walking device and a harness for safety (case 8).

Medical Dictionary for Regulatory Activities; Japanese version; MedDRA/J).

\section{Measurements}

Gait speed, step length and cadence without the HAL were measured using the $10-\mathrm{m}$ walking test (10MWT) at each session. The walking speed $(\mathrm{m} / \mathrm{s})$ and time for the 10MWT were measured using a handheld stopwatch. In addition, the number of steps from the start to the finish line were counted to calculate the step length (m). Cadence was calculated as the number of steps divided by the walking time (steps/min).The 10MWT was performed using he All-in-One Walking Trainer (without the HAL), on a flat surface, with patients walking at their comfortable pace. The Walking Index for Spinal Cord Injury (WISCI-II), ${ }^{33,34}$ the American Spinal Injury Association (ASIA) impairment scale (AIS), ${ }^{35}$ the ASIA motor score (lower extremities), and the functional independence measure (FIM) motor score (total score, 91) for activities of daily living (ADLs) ${ }^{36,37}$ were calculated at baseline and after the 10th training session. The WISCI-II scale is a 20 -item scale that measures the walking abilities of a patient based on the requirements for assistance, such as walking aids, personal assistance, or brace (grade 0, the patient has neither standing nor walking abilities; grade 20 , no assistance was needed to walk a distance of $10 \mathrm{~m}$ ). The ASIA motor score (lower extremities) is the total manual muscle testing score for five lower extremity movements (hip flexion, knee extension, ankle dorsiflexion, long toe extension, and ankle plantar flexion), with a maximum score of 25 per limb, and 50 for both lower limbs.
Surgical outcome was evaluated using the Japanese Orthopaedic Association (JOA) score and was calculated before and after surgery (total score $=11$ points). ${ }^{38}$ The JOA scoring system evaluates motor function of the lower extremity ( $0-4$ points), sensory function of the trunk ( $0-2$ points) and lower extremity (0-2 points), and bladder function ( $0-3$ points). The recovery rate in the JOA scoring system was calculated, using the method of Hirabayshi et al.,$^{39}$ as follows:

$[$ Recovery rate $=$

$$
\left.\frac{\text { Postop.JOA score }- \text { preop.JOA score }}{\text { Full score }(11)-\text { preop.JOA score }} \times 100\right] \text {. }
$$

We assessed the JOA score before surgery and at 3, 6, 9, and 12 months after surgery.

\section{Statistical analysis}

All data are expressed as a mean and standard deviation (SD). Wilcoxon signed-rank tests were used to evaluate differences between baseline measurements and outcomes after the 10 sessions. Data analyses were performed using IBM SPSS Statistics 24 software, with an alpha level set at $5 \%$.

\section{Results}

All patients completed the 10 HAL training sessions without severe and mild adverse events such as dropout, severe fatigue, and skin trouble. HAL training was initiated on postoperative day $27.5 \pm 14.1$. Cases 1, 3, 5, and 7 started treatment with HAL on postoperative days $13,13,15$, and 18 , respectively, once patients could assume the sitting position. However, cases 2, 4, 6, and 8 were advised to rest for 2 to 3 weeks as their lower extremity paralysis worsened when assuming the sitting position. Consequently, treatment for sitting was postponed and HAL training was initiated on postoperative day $44,41,43$, and 33 , respectively.

Gait speed, step length and cadence measured on the 10 MWT improved over time in all eight patients (Fig. 4 a-c, Table 2). Gait speed, step length, and cadence improved from $0.35 \pm 0.18 \mathrm{~m} / \mathrm{sec}$ to $0.85 \pm 0.23 \mathrm{~m} / \mathrm{sec}$, $0.34 \pm 0.10 \mathrm{~m}$ to $0.47 \pm 0.11 \mathrm{~m}$, and $51.9 \pm 21.5$ steps / $\min$ to $101.0 \pm 19.7$ steps $/ \mathrm{min}$, respectively. Furthermore, the mean rates of change for gait speed, step length, and cadence were $140.1 \%, 34.5 \%$, and $94.5 \%$, respectively (Table 2). Compared to baseline values, the WISCI-II also improved after 10 sessions for all patients (Fig. 5). Although the AIS remained the same, the ASIA motor score (lower extremities) and FIM motor score significantly improved after HAL 
a

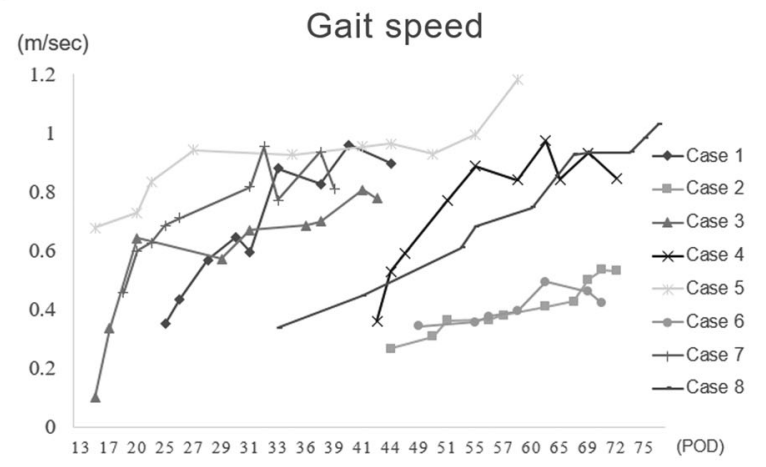

b

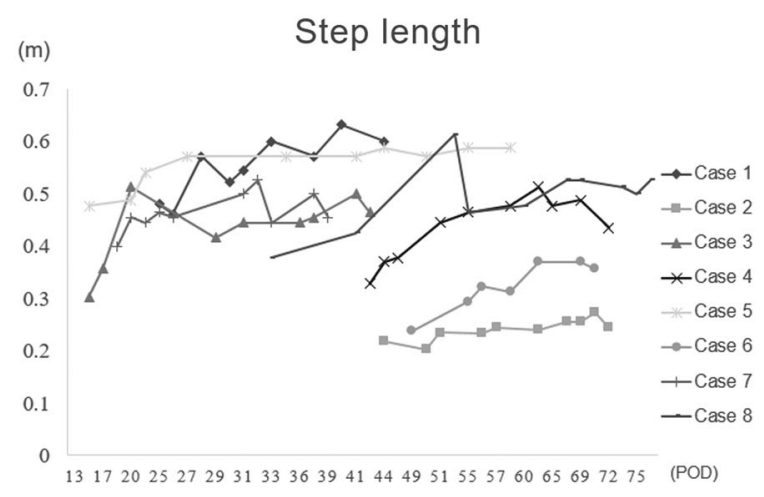

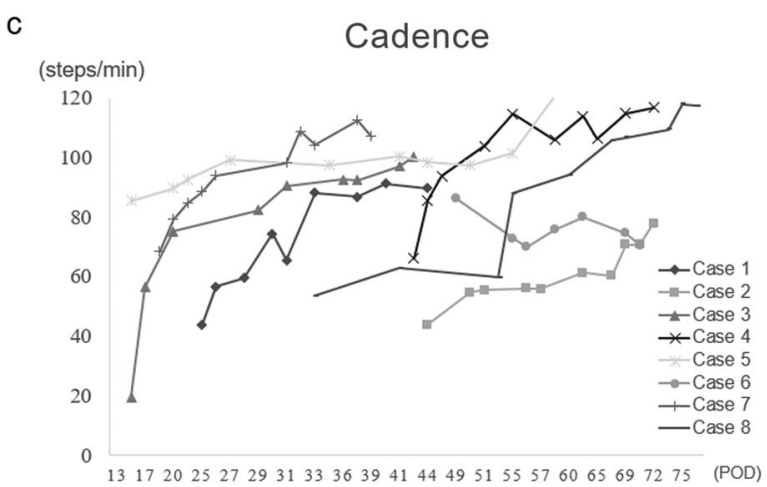

Figure 4 Results of 10-m walk test without the hybrid assistive limb (HAL). (a) gait speed, (b) step length, and (c) cadence.

training (Table 2). The JOA score before surgery and at 3, 6 , 9, and 12 months postoperatively was $3.6 \pm 1.9$ at baseline, and $6.9 \pm 1.2,7.8 \pm 1.1,8.1 \pm 1.4$, and $8.2 \pm$ 1.3 , respectively, after surgery. The improvement rate in the JOA score, from baseline, at 3, 6, 9, and 12 months post-surgery was $44.1 \pm 11.0 \%, 56.8 \pm 16.4 \%, 61.0 \pm$ $22.2 \%$, and $61.9 \pm 23.5 \%$, respectively.

\section{Discussion}

HAL training in patients with T-OPLL, presenting with severe gait disturbances, was successfully performed during the acute and subacute postoperative periods without severe adverse events, supporting the feasibility and safety of HAL training for this clinical population. Compared to baseline, gait speed, step length and cadence improved over time, as well as an increase in the WISCI-II, ASIA motor score (lower extremities), and JOA scores measured after the 10session training program. Our findings also support the efficacy of HAL training, initiated in the early postoperative period, in improving walking outcomes in patients with T-OPLL-associated severe locomotor disorder.

Neurological recovery of the myelopathy after PDF in patients with T-OPLL is slow. In this study, the recovery rate, based on the JOA scores, were $44.1 \%, 56.8 \%$, $61.0 \%$, and $61.9 \%$ which is higher than the recovery rate of $36.7 \%, 48.8 \%, 54.0 \%$, and $56.8 \%$ at $3,6,9$,

Table 2 The results of the gait speed, step length, cadence, the American Spinal Injury Association (ASIA) impairment scale (AIS), ASIA motor score (lower extremities), and functional independent measure (FIM) motor score at baseline and after 10 sessions.

\begin{tabular}{|c|c|c|c|c|}
\hline & Baseline & After 10 sessions & $P$ value & Statistical power \\
\hline Gait speed (m/sec) & $0.35 \pm 0.18$ & $0.85 \pm 0.23$ & $P=0.01$ & $98.5 \%$ \\
\hline Step length (m) & $0.34 \pm 0.10$ & $0.47 \pm 0.11$ & $P=0.01$ & $40.9 \%$ \\
\hline Cadence (steps/min) & $51.9 \pm 21.5$ & $101.0 \pm 19.7$ & $P=0.01$ & $97.0 \%$ \\
\hline AIS & $\mathrm{D}$ & $\mathrm{D}$ & NA & NA \\
\hline ASIA motor score (lower extremities) & $33.9 \pm 4.6$ & $42.0 \pm 5.8$ & $P=0.01$ & $69.1 \%$ \\
\hline FIM motor & $48.9 \pm 14.0$ & $79.9 \pm 8.9$ & $P=0.02$ & $98.3 \%$ \\
\hline
\end{tabular}

AIS, ASIA impairment scale; ASIA, American spinal injury association; FIM, functional independent measure; NA, not applicable. 


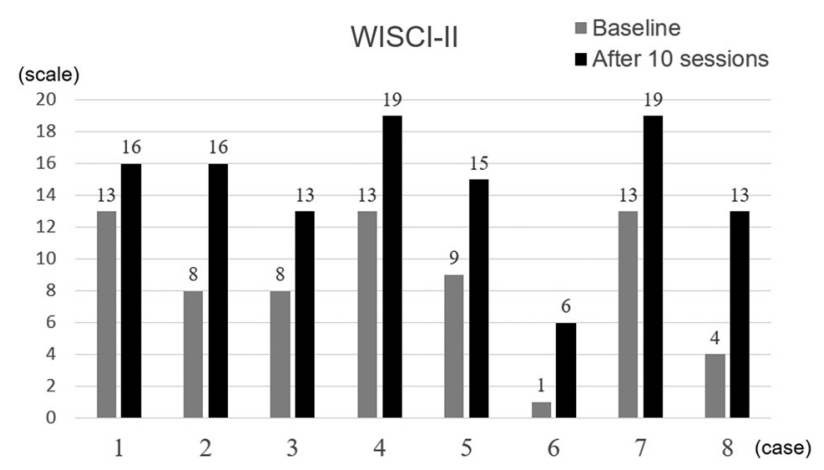

Figure 5 Walking index for spinal cord injury (WISCI) II at baseline and after 10 sessions.

12-months post-surgery reported in a previous study. ${ }^{38}$ In a previous study, postoperative conventional rehabilitation by therapists such as sitting exercises, sitting and standing, gait training, and ADL training were implemented in patients with T-OPLL. ${ }^{38}$ Improvement in recovery rate according to JOA score $(\mathrm{P}=0.07)$ was observed in both groups (Fig. 6). On the other hand, the average JOA score in our study was 3.6 before surgery. We showed that the average JOA score before surgery is lower than the average in severe cases (our study: three cases, previous study: 15 cases), and that were compared in both groups. As a consequence, the recovery rate of JOA had significant improved in 12 postoperative months (our study: $80.7 \pm 10.0 \%$, previous study: $58.1 \pm 4.5 \%, \quad \mathrm{P}=0.03$ ) (Fig. 7). Therefore, HAL training has the potential to improve patients with T-OPLL postoperatively. We consider that the significant improvement in severe cases might have important clinical implications. Sakakima et al. also evaluated a program of gait training using the

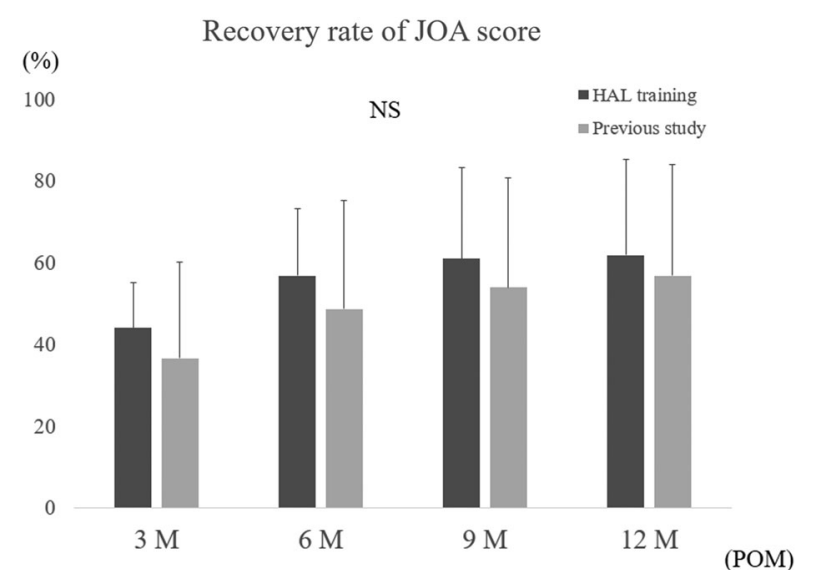

Figure 6 The results of recovery rate of JOA (Japanese Orthopaedic Association) score after surgery. The recovery rate of JOA scores after surgery in HAL training was higher than in a previous study. ${ }^{38}$
HAL (6 session per week, for 8 weeks), initiated a post-operative week 8 , in patients with T-OPLL-associated severe gait disturbance and prolonged paralysis, even after surgery. ${ }^{29}$ They also reported a significant improvement in walking ability and lower extremity muscle strength, with a conclusion that HAL training facilitated recovery of lower extremity function. ${ }^{29}$ In our study, the early introduction of HAL training (at 3-4 weeks post-surgery) remarkably improved the walking ability in a relatively short period of time.

Barbeau reported on the importance of proper sensory input in the process of recovery of spinal cord injury and stroke. ${ }^{40}$ Appropriate sensory inputs (e.g. loading the maximum weight, facilitating proper trunk posture and hip extension, and proper loadingunloading) are essential to achieve maximum functional recovery. $\mathrm{Wu}$ et al. reported that locomotor treatment using an original cable-driven robotic locomotor support system improved the walking speed and balance in patients with chronic incomplete spinal cord injury and chronic stroke. ${ }^{41,42}$ As a cabledriven robotic locomotor system constrains leg movement and allows variability in leg kinematics during treadmill walking, cable-driven assistive training is essential in motor learning.

HAL has two control methods: a CVC system and a cybernic autonomous control (CAC) system. The CVC system controls the actuators based on the bioelectric signals detected on the skin surface and, therefore, assists the wearer's voluntary movements. In contrast,

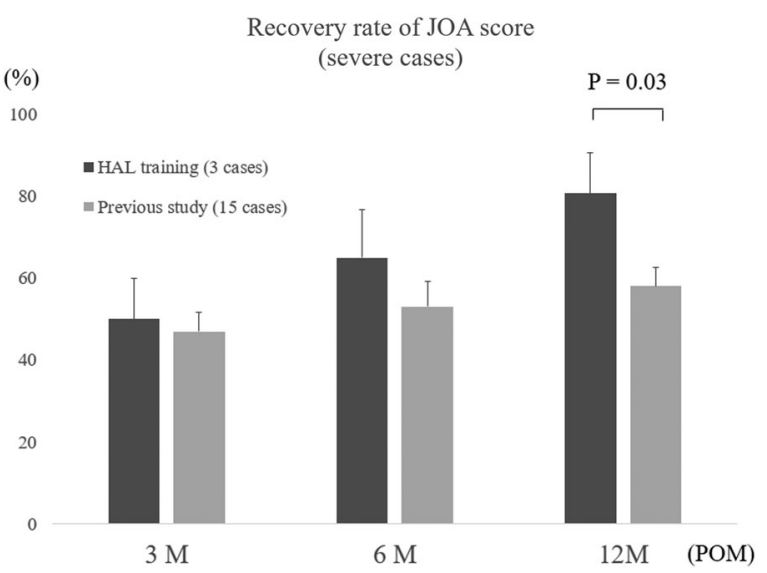

Figure 7 The results of recovery rate of JOA (Japanese Orthopaedic Association) score in severe cases after surgery (our study: three cases, previous study: 15 cases). The recovery rate of JOA scores in severe cases after surgery in HAL training was higher than in a previous study. ${ }^{38}$ The recovery rate of JOA had significant improvement in 12 POM (our study: $80.7 \pm$ $10.0 \%$, previous study: $58.1 \pm 4.5 \%, P=0.03$ ). POM: postoperative month. 


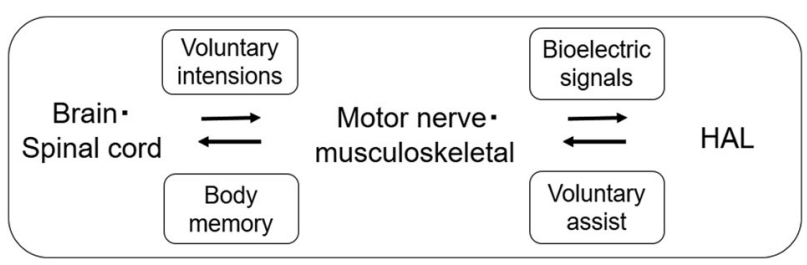

Figure 8 Hybrid assistive limb (HAL) motion support technologies. An interactive biofeedback system that links the brain/nervous system, body, and HAL (i.e. brain $\rightarrow$ spinal cord $\rightarrow$ motor nerve $\rightarrow$ musculoskeletal $\rightarrow$ HAL; HAL $\rightarrow$ musculoskeletal $\rightarrow$ motor nerve $\rightarrow$ spinal cord $\rightarrow$ brain) enables errorless motor learning.

the CAC system drives actuators using preprogramed walking patterns in humans, based on loading information detected by force-pressure sensors in the shoes. In these HAL motion support technologies, an interactive biofeedback system links the brain/nervous system body to the HAL (i.e. brain $\rightarrow$ spinal cord $\rightarrow$ motor nerve $\rightarrow$ musculoskeletal $\rightarrow$ HAL; HAL $\rightarrow$ musculoskeletal $\rightarrow$ motor nerve $\rightarrow$ spinal cord $\rightarrow$ brain), providing errorless motor learning (Fig. 8). The HAL can enhance movement by expressing the wearer's voluntary muscle activity as actual motion. Thus, locomotor training using HAL is expected to improve wearer's operational capacity by feeding back the behaviors thought to be more desirable back to the HAL motion support. From a clinical perspective, the HAL also reduces the physical burden on therapists by avoiding the need for hands-on control of lower limb motion, providing a more satisfactory rehabilitation for patients and therapists.

\section{Study limitations}

As we evaluated gait recovery in patients with T-OPLL after surgery, it is not possible to distinguish recovery due to the surgery itself from the effect of HAL training. To evaluate the specific effect of HAL training, the study should be repeated with chronic cases of OPLL in whom symptomatic improvement would have reached a plateau. However, from a clinical perspective, providing intervention during the acute and subacute postoperative periods was more effective and necessary. In addition, since the study design is a single group safety and feasibility test, measured effects cannot be causally attributed to the HAL training. A randomized controlled trial, using a comparative control group, is warranted to provide high level evidence regarding the efficacy of HAL training. Lastly, the same examiner performed the evaluation and treatment and, therefore, the effects examiner/ subject bias cannot be ruled out.

\section{Conclusion}

The results of this study confirmed the safety and feasibility of using the HAL for the rehabilitation from severe myelopathy due to T-OPLL.

\section{Acknowledgments}

We thank Mayuko Sakamaki and Yumiko Ito of the Center for Innovative Medicine and Engineering (CIME) at the University of Tsukuba Hospital for their excellent technical assistance.

\section{Disclaimer statements}

Funding This study was supported by the Industrial Disease Clinical Research Grants of the Ministry of Health Labour and Welfare, Japan (14060101-01).

\section{Declaration of interest None.}

Conflicts of interest A commercial party having a direct financial interest in the results of the research and supporting this article has conferred or will confer a financial benefit on one or more of the authors. One author is the CEO of Cyberdyne Inc, Ibaraki, Japan, which is the manufacturer of the robot suit HAL. Cyberdyne Inc was not directly involved in the study design; the collection, analysis, or interpretation of data; writing the report; or the decision to submit the paper for publication. No commercial party having a direct financial interest in the results of the research supporting this article has or will confer a benefit on the authors or on any organization with which the authors are associated.

Informed consent Patients who agreed to participate in this study provided both oral and written informed consents.

Ethical approval The study was approved by the Institutional Review Board (IRB) of each institution involved in this study and was conducted according to the principles of the World Medical Association (WMA) Declaration of Helsinki-Ethical Principles for Medical Research Involving Human Subjects with the amendments made in Seoul, South Korea, in October 2008, with a note of clarification on paragraph 29 added by the WMA General Assembly in Washington (2002) and a note of clarification on paragraph 30 added by the WMA General Assembly in Tokyo (2004). This study was also conducted in accordance with the Japanese Medical Research Involving Human Subjects Act (WMO) and other guidelines, regulations, and acts. This study was registered with the University Hospital Medical Information Network (UMIN) Clinical Trials Registry (UMIN000014336). 
Supplemental data for this article can be accessed on the publisher's website https://doi.org/10.1080/10790268. 2018.1525975.

\section{ORCID}

Shigeki Kubota (D) http://orcid.org/0000-0003-44554585

Yukiyo Shimizu (1) http://orcid.org/0000-0001-74914516

Hiroki Watanabe (1) http://orcid.org/0000-0002-44365437

\section{References}

1 Abiola R, Rubery P, Mesfin A. Ossification of the posterior longitudinal ligament: etiology, diagnosis, and outcomes of nonoperative and operative management. Global Spine J 2016;6(2):195-204.

2 Kawamoto H, Sankai Y. Power assist method based on phase sequence and muscle force condition for HAL. Adv Robot 2005; 19(7):717-34.

3 Lee S, Sankai Y. Virtual impedance adjustment in unconstrained motion for an exoskeletal robot assisting the lower limb. Abv Robot 2005;19(7):773-95.

4 Suzuki K, Gouji M, Kawamoto H, Hasegawal Y, Sankai K. Intention-based walking support for paraplegia patients with robot suit HAL. Adv Robot 2007;21(12):1441-69.

5 Tsukahara A, Kawanishi R, Hasegawa Y, Sankai Y. Sit-to-stand and stand-to-sit transfer support for complete paraplegic patients with robot suit HAL. Adv Robot 2010;24(11):1615-38.

6 Kubota S, Nakata Y, Eguchi K, Kawamoto H, Kamibayashi K, Sakane M, et al. Feasibility of rehabilitation training with a newly developed wearable robot for patients with limited mobility. Arch Phys Med Rehabil 2013;94(6):1080-7.

7 Michikawa T, Nishiwaki Y, Takebayashi T, Toyama Y. One-leg standing test for elderly populations. J Orthop Sci 2009;14(5):675-85.

8 Cruciger O, Tegenthoff M, Schwenkreis P, Schildhauer TA, Aach M. Locomotion training using voluntary driven exoskeleton (HAL) in acute incomplete SCI. Neurology 2014;83(5):474.

9 Aach M, Cruciger O, Sczesny-Kaiser M, Höffken O, Meindl R, Tegenthoff M, et al. Voluntary driven exoskeleton as a new tool for rehabilitation in chronic spinal cord injury: a pilot study. Spine J 2014;14(12):2847-53.

10 Sczesny-Kaiser M, Höffken O, Aach M, Cruciger D, Grasmücke $\mathrm{D}$, Meindl $\mathrm{R}$, et al. HAL ${ }^{\circledR}$ exoskeleton training improves walking parameters and normalizes cortical excitability in primary somatosensory cortex in spinal cord injury patients. J Neuroeng Rehabil 2015;12:68.

11 Cruciger O, Schildhauer TA, Meindl RC, Tegenthoff M, Schwenkreis P, Citak M, et al. Impact of locomotion training with a neurologic controlled hybrid assistive limb (HAL) exoskeleton on neuropathic pain and health related quality of life (HRQoL) in chronic SCI: a case study. Disabil Rehabil Assist Technol 2016; 11(6):529-34.

12 Ikumi A, Kubota S, Shimizu Y, Kadone H, Marushima A, Ueno $\mathrm{T}$, et al. Decrease of spasticity after hybrid assistive $\operatorname{limb}\left({ }^{\circledR}\right)$ training for a patient with $\mathrm{C} 4$ quadriplegia due to chronic SCI. J Spinal Cord Med 2016;20(5):1-6.

13 Shimizu Y, Nakai K, Kadone H, Yamauchi S, Kubota S, Ueno T, et al. The Hybrid Assistive Limb ${ }^{\circledR}$ intervention for a postoperative patient with spinal dural arteriovenous fistula and chronic spinal cord injury: a case study. J Spinal Cord Med 2017;29:1-8.

14 Shimizu Y, Kadone H, Kubota S, Ikumi A, Abe T, Marushima A, et al. Active elbow flexion is possible in $\mathrm{C} 4$ quadriplegia using hybrid assistive limb (HAL $\mathbb{R})$ technology: a case study. J Spinal Cord Med 2017;40(4):456-62.

15 Maeshima S, Osawa A, Nishio D, Hirano Y, Takeda K, Kigawa H, et al. Efficacy of a hybrid assistive limb in post-stroke hemiplegic patients: a preliminary report. BMC Neurol 2011;11:116.
16 Kawamoto H, Kamibayashi K, Nakata Y, Yamawaki K, Ariyasu $\mathrm{R}$, Sankai $\mathrm{Y}$, et al. Pilot study of locomotion improvement using hybrid assistive limb in chronic stroke patients. BMC Neurol 2013;13:141.

17 Watanabe $H$, Tanaka $N$, Inuta $T$, Saitou $H$, Yanagi $H$. Locomotion improvement using a hybrid assistive limb in recovery phase stroke patients: a randomized controlled pilot study. Arch Phys Med Rehabil 2014;95(11):2006-12.

18 Nilsson A, Vreede KS, Häglund V, Kawamoto H, Sankai T, Borg J. Gait training early after stroke with a new exoskeleton - the hybrid assistive limb: a study of safety and feasibility. J Neuroeng Rehabil 2014;11:92.

19 Mizukami M, Yoshikawa K, Kawamoto H, Sano A, Koseki K, Asakwa Y, et al. Gait training of subacute stroke patients using a hybrid assistive limb: a pilot study. Disabil Rehabil Assist Technol 2017;12(2):197-204.

20 Yoshikawa K, Mizukami M, Kawamoto H, Sano A, Koseki K, Sano K, et al. Gait training with hybrid assistive limb enhances the gait functions in subacute stroke patients: a pilot study. Neuro Rehabilitation 2017;40(1):87-97.

21 Ueba T, Hamada O, Ogata T, Inoue T, Shiota E, Sankai Y. Feasibility and safety of acute phase rehabilitation after stroke using the hybrid assistive limb robot suit. Neurol Med Chir 2013;53(5):287-90.

22 Fukuda H, Morishita T, Ogata T, Saita K, Hyakutake K, Watanabe $\mathbf{J}$, et al. Tailor-made rehabilitation approach using multiple types of hybrid assistive limb robots for acute stroke patients: a pilot study. Assist Technol 2016;28(1):53-6.

23 Yoshioka T, Sugaya H, Kubota S, Onishi M, Kanamori A, Sankai Y, et al. Knee-extension training with a single-joint hybrid assistive limb during the early postoperative period after total knee arthroplasty in a patient with osteoarthritis. Case Rep Orthop 2016;2016:9610745.

24 Yoshioka T, Kubota S, Sugaya H, Hyodo K, Ogawa K, Taniguchi $\mathrm{Y}$, et al. Robotic device-assisted knee extension training during the early postoperative period after opening wedge high tibial osteotomy: a case report. J Med Case Rep 2017;11:213.

25 Goto K, Morishita T, Kamada S, Saita K, Fukuda H, Shiota E. Feasibility of rehabilitation using the single-joint hybrid assistive limb to facilitate early recovery following total knee arthroplasty: a pilot study. Assist Technol 2016;10(4):1-5.

26 Tanaka Y, Oka H, Nakayama S, Ueno T, Matsudaira K, Miura T, et al. Improvement of walking ability during postoperative rehabilitation with the hybrid assistive limb after total knee arthroplasty: a randomized controlled study. SAGE Open Med 2017;5: 205031211771288.

27 Kubota S, Hara Y, Shimizu Y, Kadone H, Kubo T, Marushima A, et al. A newly developed upper limb single-joint HAL in a patient with elbow flexion reconstruction after traumatic brachial plexus injury: a case report. Interdiscip Neurosurg 2017;10:66-8.

28 Wall A, Borg J, Palmcrantz S. Clinical application of the hybrid assistive limb (HAL) for gait training-a systematic review. Front Syst Neurosci 2015;9:48.

29 Sakakima H, Ijiri K, Matsuda F, Tominaga H, Biwa T, Yone K, et al. A newly developed robot suit hybrid assistive limb facilitated walking rehabilitation after spinal surgery for thoracic ossification of the posterior longitudinal ligament: a case report. Case Rep Orthop 2013;2013:621405.

30 Fujii K, Abe T, Kubota S, Marushima A, Kawamoto H, Uneno T, et al. The voluntary driven exoskeleton Hybrid Assistive Limb (HAL) for postoperative training of thoracic ossification of the posterior longitudinal ligament: a case report. J Spinal Cord Med 2017;40(3):361-7.

31 Kubota S, Abe T, Fujii K, Marushima A, Ueno T, Haginoya A, et al. Improvement of walking ability using hybrid assistive limb training in a patient with severe thoracic myelopathy caused by ossification of the posterior longitudinal ligament - a case report. J Spine 2016;S7:003.

32 Kubota S, Abe T, Kadone H, Fuji K, Shimizu Y, Marushima A, et al. Walking ability following hybrid assistive limb treatment for a patient with chronic myelopathy after surgery for cervical ossification of the posterior longitudinal ligament. J Spinal Cord Med 2017;20:1-9.

33 Ditunno JF Jr, Ditunno PL, Scivoletto G, Patrick M, Dijikers M, Barbeau $\mathrm{H}$, et al. The walking index for spinal cord injury 
(WISCI/WISCI II): nature, metric properties, use and misuse. Spinal Cord 2013;51:346-55.

34 Scivoletto G, Tamburella F, Laurenza L, Torre M, Molinari M, Ditunno JF. Walking index for spinal cord injury version II in acute spinal cord injury: reliability and reproducibility. Spinal Cord 2014;52:65-9.

35 Kirshblum SC, Burns SP, Biering-Sorensen F, Donovan W, Graves $\mathrm{DE}$, Jha $\mathrm{A}$, et al. International standards for neurological classification of spinal cord injury (revised 2011). J Spinal Cord Med 2011;34(6):535-46.

36 Linacre JM, Heinemann AW, Wright BD, Granger CV, Hamilton $\mathrm{BB}$. The structure and stability of the functional independence measure. Arch Phys Med Rehabil 1994;75:127-32.

37 Tsuji T, Sonoda S, Domen K, Saitoh N, Liu M, Chino N. ADL structure for stroke patients in Japan based on the functional independence measure. Am J Phys Med Rehabil 1995;74(6): $432-8$.

38 Yamazaki M, Okawa A, Fujiyoshi T, Furuya T, Koda M. Posterior decompression with instrumented fusion for thoracic myelopathy caused by ossification of the posterior longitudinal ligament. Eur Spine J 2010;19(5):691-8.

39 Masaki Y, Yamazaki M, Okawa A, Aramoni M, Hahimoto M, Koda M, et al. An analysis of factors causing poor surgical outcome in patients with cervical myelopathy due to ossification of the posterior longitudinal ligament: anterior decompression with spinal fusion versus laminoplasty. J Spinal Disord Tech 2007;20(1):7-13.

40 Barbeau H. Locomotor training in neurorehabilitation: emerging rehabilitation concepts. Neurorehabil Neural Repair 2003;17(1):3-11.

$41 \mathrm{Wu}$ M, Landry JM, Kim J, Schmidt BD, Yen SC, McDonald J. Robotic resistance/assistance training improves locomotor function in individuals post stroke: a randomized controlled study. Arch Phys Med Rehabil 2014;95(5):799-806.

$42 \mathrm{Wu}$ M, Landry JM, Kim J, Schmidt B, Yen SC, McDonald J, et al. Repeat exposure to leg swing perturbations during treadmill training induces long-term retention of increased step length in human SCI: a pilot randomized controlled study. Am J Phys Med Rehabil 2016;95(12):911-20. 